\title{
Visual discrimination training improves Humphrey perimetry in chronic cortically induced blindness OPEN
}

Matthew R. Cavanaugh, MS

Krystel R. Huxlin, PhD

Correspondence to

Dr. Huxlin:

huxlin@cvs.rochester.edu

Supplemental data at Neurology.org

\section{ABSTRACT}

Objective: To assess if visual discrimination training improves performance on visual perimetry tests in chronic stroke patients with visual cortex involvement.

Methods: 24-2 and 10-2 Humphrey visual fields were analyzed for 17 chronic cortically blind stroke patients prior to and following visual discrimination training, as well as in 5 untrained, cortically blind controls. Trained patients practiced direction discrimination, orientation discrimination, or both, at nonoverlapping, blind field locations. All pretraining and posttraining discrimination performance and Humphrey fields were collected with online eye tracking, ensuring gaze-contingent stimulus presentation.

Results: Trained patients recovered $\sim 108$ degrees $^{2}$ of vision on average, while untrained patients spontaneously improved over an area of $\sim 16$ degrees $^{2}$. Improvement was not affected by patient age, time since lesion, size of initial deficit, or training type, but was proportional to the amount of training performed. Untrained patients counterbalanced their improvements with worsening of sensitivity over $\sim 9$ degrees $^{2}$ of their visual field. Worsening was minimal in trained patients. Finally, although discrimination performance improved at all trained locations, changes in Humphrey sensitivity occurred both within trained regions and beyond, extending over a larger area along the blind field border.

Conclusions: In adults with chronic cortical visual impairment, the blind field border appears to have enhanced plastic potential, which can be recruited by gaze-controlled visual discrimination training to expand the visible field. Our findings underscore a critical need for future studies to measure the effects of vision restoration approaches on perimetry in larger cohorts of patients.

Neurology ${ }^{\circledR}$ 2017;88:1856-1864

\section{GLOSSARY}

ANOVA = analysis of variance; $\mathbf{C B}=$ cortically induced blindness; $\mathbf{C l}=$ confidence interval; $\mathbf{d L G N}=$ dorsal lateral geniculate nucleus; HVF = Humphrey visual field; PD = pattern deviation; PMD = perimetric mean deviation; $\mathbf{S T F}=$ short term fluctuations; UCB = untrained cortically induced blindness.

Stroke damage to the primary visual cortex (V1) is a major cause of vision loss in humans. Clinically, cortically induced blindness (CB) is assessed with Goldmann, Humphrey, and other forms of visual perimetry, presenting as homonymous defects contralateral to the damaged brain hemisphere.

While substantial spontaneous recovery can occur in the first few weeks to months postdamage, CB defects are then thought to become stable and permanent. ${ }^{1}$ Patients are commonly sent home without visual rehabilitation, and when therapy is recommended, it tends to focus on developing compensatory eye movement strategies ${ }^{2}$ or on using substitution, such as prism lenses. ${ }^{3}$ Although able to improve visual functioning and quality of life, neither form of therapy alters the visual defect. ${ }^{4}$ In fact, there is currently no widely accepted clinical method to restore vision in $\mathrm{CB},{ }^{5}$ although multiple research studies have shown visual training to recover particular functions within chronic CB fields (see Melnick et al. ${ }^{6}$ for review). However, whether restitution therapies improve perimetry has been relatively little explored, and results vary widely. In addition, some

From the Flaum Eye Institute, University of Rochester, NY.

Go to Neurology.org for full disclosures. Funding information and disclosures deemed relevant by the authors, if any, are provided at the end of the article. The Article Processing Charge was funded by the NIH.

This is an open access article distributed under the terms of the Creative Commons Attribution-NonCommercial-NoDerivatives License 4.0 (CC BY-NC-ND), which permits downloading and sharing the work provided it is properly cited. The work cannot be changed in any way or used commercially without permission from the journal. 
prior studies were confounded by poor standards and controls, ${ }^{7,8}$ while others yielded promising results. ${ }^{9-16}$ As such, significant controversy remains about the ability of restitution therapy to improve cortically blind visual fields.

The goal of the present study was to quantify the effect of visual discrimination training on Humphrey automated perimetry in chronic CB. We performed a retrospective analysis of Humphrey visual fields (HVFs) from patients with chronic $\mathrm{CB}$ trained using the Huxlin discrimination paradigm, with performance measured using online fixation control. ${ }^{16-18}$ Changes in pretraining/posttraining HVFs were also compared with those from HVFs collected at 2 time points prior to the onset of training-i.e., in untrained $\mathrm{CB}$ (UCB) controls. Our data suggest significant benefits of visual training for perimetry in chronic $\mathrm{CB}$, which warrant further exploration in controlled clinical trials.

METHODS Participants. HVFs were analyzed retrospectively from 24 patients with CB (table e-1 at Neurology.org), recruited for visual retraining. ${ }^{16-18}$ Inclusion criteria were adults at least 6 months after stroke-induced occipital damage (verified using structural MRIs), with reliable 24-2 and 10-2 HVFs $(<20 \%$ fixation losses, false-positive and false-negative errors) in both eyes and ability to fixate precisely (error smaller than \pm 1 degree relative to fixation spot) during psychophysical testing. Exclusion criteria were unreliable HVFs, ocular disease, neglect, neurologic disease unrelated to occipital stroke, use of neuroactive drugs, and inability to fixate precisely (error greater than \pm 1 degree relative to fixation spot) during psychophysical testing. In 5 patients (UCB1-UCB5), 2 HVFs were collected before training, allowing assessment of HVF stability. UCB1 then completed training and was designated CB1. UCB2-UCB5 failed to complete training or to generate reliable posttraining HVFs (appendix $\mathrm{e}-1)$; thus, they were not included in our trained cohort. Three participants, who successfully completed pretraining tests and training, then failed to obtain reliable HVFs posttraining and were excluded from the analysis. As such, the data presented include 5 untrained and 17 trained CB patients.

Standard protocol approvals, registrations, and patient consents. All patient-related procedures performed in the presented study were approved by the Institutional Review Board of the University of Rochester Medical Center. Testing and training were conducted after obtaining written informed consent from each participant.

Experimental design. HVFs were collected by a single ophthalmic technician, who was blinded to each participant's training status. Psychophysical testing by laboratory personnel was then used to establish training locations, as described previously. ${ }^{16-18}$ UCB1-UCB5 repeated HVFs after 1.4-13.3 months before training (table e-1). CB1-CB17 trained for 3-14 months before returning to the laboratory for verification of training performance and to repeat HVFs (table e-1).

Training. Patients trained on left-right direction discrimination of random dot stimuli $(\mathrm{n}=6)$, vertical-horizontal orientation discrimination of static Gabors $(\mathrm{n}=5)$, or both tasks $(\mathrm{n}=6)$ at nonoverlapping, blind field locations (table e-1), as previously described. ${ }^{16-18}$ Stimuli and task details are also provided in appendix e-1 and illustrated in figure e-1, A and $\mathrm{B}$. Training locations were chosen as sites where performance first dropped to chance $(50 \%$ correct) during blind field border mapping. Patients trained at home, performing 300 trials per day, per location, at least 5 days per week. They e-mailed data log files automatically generated by the training software back to the laboratory for analysis weekly. Once performance became comparable to that at equivalent, intact field locations (measured during pretests), training moved 1 degree deeper into the blind field along the $\mathrm{X}$-axis (Cartesian coordinate space). While home training was performed without an eye tracker, patients were instructed to fixate whenever a fixation spot was present. In addition, after 6 months of training, or recovering normal discrimination performance at $\geq 2$ blind field locations, home training was verified in laboratory with fixation control enforced using an Eyelink 1000 eye tracker (SR Research Ltd., Kanata, Canada).

Quantitative analysis of HVFs. HVFs were collected as detailed in appendix e- 1 and several metrics calculated by the Humphrey STATPAC software (Zeiss Humphrey Systems, Atlanta, GA) were analyzed as follows:

1. Pattern deviation (PD): deviation from the age-corrected population mean for each HVF testing location.

2. Perimetric mean deviation (PMD): overall difference in sensitivity between the tested and expected hill of vision for an age-corrected, normal population.

3. Short term fluctuations (STF): test/retest variance during 10-2 HVF test.

Composite, binocular HVFs were generated in MATLAB (MathWorks, Inc., Natick, MA) by first averaging luminance detection thresholds $(\mathrm{dB})$ from monocular HVFs at identical test locations between both eyes (figure e-2A), justified given the homonymous nature of the deficit. These binocular 24-2 and 10-2 HVFs were then combined (figure e-2A), with 5 overlapping locations averaged together (green dots, figure e-2A). Natural-neighbor interpolation was applied between test locations with 0.1 degree $^{2}$ resolution, creating composite visual fields of 121 tested locations and 161,398 interpolated data points, covering an area 1,616 degrees ${ }^{2}$ in size. Difference maps were generated (figure e-2B) by subtracting the initial, composite, noninterpolated HVF from the second HVF, then interpolating the difference to create a smooth map of visual sensitivity change (trained patients: figure e-3; untrained patients: figure e-4). From these difference maps, we calculated the following:

1. Area of HVF-defined visual deficit: impaired region defined by $\mathrm{PD}<-5 \mathrm{~dB}$.

2. Area of HVF where sensitivity changed by $\geq 6 \mathrm{~dB}$ : improved regions had luminance sensitivity that increased by $\geq 6 \mathrm{~dB}$ relative to baseline; worsened regions had sensitivity that dropped by $\geq 6 \mathrm{~dB}$. The $6 \mathrm{~dB}$ value was selected as it was roughly double the 24-2 HVF test/retest variability (Humphrey STATPAC, Zeiss Humphrey Systems), and the STFs measured during 10-2 HVFs (figure e-5A).

Primary outcome measures were changes in PMD and the area of the HVF where sensitivity increased or decreased by $\geq 6 \mathrm{~dB}$. The secondary outcome measure was the change in performance on the training tasks. 
Figure 1 Effects of discrimination training on Humphrey visual field (HVF)derived metrics
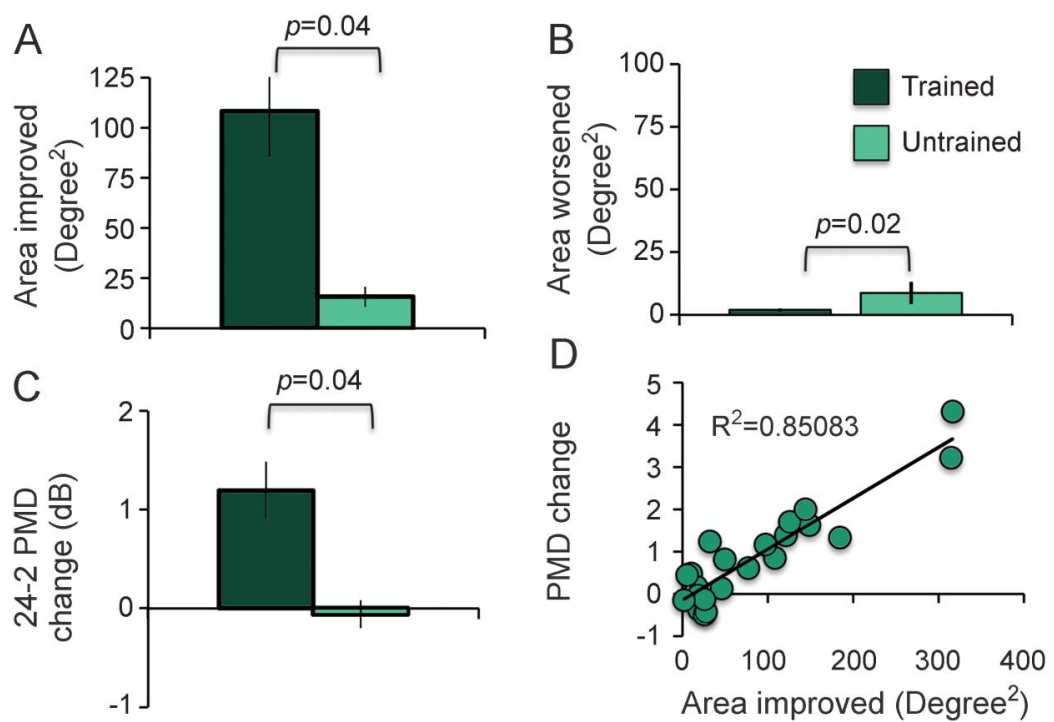

(A) Area of the HVF that improved by $\geq 6 \mathrm{~dB}$ in trained and untrained participants. (B) Area of the HVF that worsened by $\geq 6 \mathrm{~dB}$ in trained and untrained participants. (C) Change in perimetric mean deviation (PMD) averaged across the 2 eyes, computed from 24-2 HVF. (D) Positive correlation between the area of the HVF that improved by $\geq 6 \mathrm{~dB}$ (from A) with the change in PMD (from $C$ ). Values in $A-C$ are means \pm SEM.

Statistical analyses. Values provided are mean \pm SEM and 95\% confidence intervals (CI), with 2-tailed $t$ tests or analyses of variance (ANOVAs) used to assess significance using $p<0.05$ (VassarStats.net). Post hoc power analyses for relevant $t$ test comparisons were performed for the primary and secondary outcomes using G*Power (version 3.1.9.2), and outcomes are reported in the Results.

RESULTS Effect of training on the trained tasks. Except for CB1, CB2, CB5, CB13, and CB17, training results were published previously (Huxlin et al., 2009 ${ }^{16}$; Das et al., 2014 $4^{17}$ ). Before training, participants could not reliably perform discriminations within the blind field (gray bars, figure e-1, C and D), despite excellent intact field performance (white bars, figure e-1, C and D). Pretraining blind and intact field performances were found to be different (paired $t$ tests, direction discrimination: $t_{11}=10.74$ $p<0.0001$; orientation discrimination: $t_{10}=11.28$, $p<0.0001$ ). Posttraining performance (black bars, figure e-1, C and D) reached $81 \pm 2 \%$ correct for direction discrimination after $62 \pm 12$ sessions, and $87 \pm 2.5 \%$ correct for orientation discrimination after $30 \pm 11$ sessions, an improvement over pretraining values (paired $t$ tests, direction: $t_{11}=6.83$, $p<0.0001, \mathrm{CI}_{95}= \pm 6.22 \%$; orientation: $t_{10}=$ 7.93, $\left.p<0.0001, \mathrm{CI}_{95}= \pm 7.5 \%\right)$. Post hoc analyses revealed $97 \%$ power for both these comparisons.

Effect of training vs no training on HVFs. Pretraining, Humphrey-derived metrics revealed no significant baseline differences between trained and untrained groups (figure e-5). After training, luminance detection sensitivity improved $\geq 6 \mathrm{~dB}$ over $108.1 \pm 22.8$ degrees $^{2}$ (see figure e-3 for individual maps), greater than the area improved $\left(16 \pm 5\right.$ degrees $\left.^{2}\right)$ in untrained controls (figure 1A, figure 2, see figure e-4 for individual maps; independent $t$ test, unequal variance: $t_{17.5}$ $=17.49, p=0.001, \mathrm{CI}_{95}= \pm 49.4$ degrees $\left.^{2}\right)$. Post hoc analysis revealed $83 \%$ power for this comparison. In untrained patients, sensitivity improved by up to $14.5 \mathrm{~dB}(7.3 \pm 0.1 \mathrm{~dB})$, less (independent $t$ test: $t_{20}=$ $3.46, p=0.003)$ than trained patients, who improved by up to $28 \mathrm{~dB}(9.48 \pm 0.4 \mathrm{~dB})$.

Both groups also had locations that worsened $\geq 6 \mathrm{~dB}$. Worsening occurred in $59 \%$ of trained patients $(n=10 / 17)$ but $80 \%$ of untrained patients $(\mathrm{n}=4 / 5)$. The average area of worsening in trained patients was $1.9 \pm 0.7$ degrees $^{2}$, smaller (independent $t$ test: $t_{20}=-2.62, p=0.016, \mathrm{CI}_{95}= \pm 5.4 \mathrm{de}-$ grees $^{2}$ ) than the $8.7 \pm 4.5$ degrees $^{2}$ area of decreased sensitivity in untrained patients (figure 1B). The magnitude of worsening was similar in untrained $(-7.3 \pm 0.2 \mathrm{~dB})$ and trained patients $(-7.1 \pm$ $0.2 \mathrm{~dB}$; independent $t$ test: $\left.t_{13}=-0.34, p=0.74\right)$.

The luminance sensitivity improvements in trained patients increased PMD by $1.2 \pm 0.29 \mathrm{~dB}$ in the $24-2$ $\mathrm{HVF}$ (figure $1 \mathrm{C}$ ). In contrast, PMDs of untrained controls decreased by $0.06 \pm 0.14 \mathrm{~dB}$, a substantial difference from trained patients (independent $t$ test, unequal variance: $t_{19.8}=3.79, p=0.0012, \mathrm{CI}_{95}=$ $0.67 \mathrm{~dB}$ ). Post hoc analysis revealed $86 \%$ power for this comparison. Moreover, PMD change correlated tightly with our computed area of improvement (figure $1 \mathrm{D}$, linear correlation, $r=0.9224$, independent $t$ test: $\left.t_{20}=10.68, p<0.0001\right)$.

Effect of type of training. Double-trained patients ( $\mathrm{n}=$ 6) exhibited improvements over $114 \pm 20$ degrees $^{2}$, while orientation $(n=5)$ and direction $(n=6)$ trained patients improved over $101 \pm 56$ degrees $^{2}$ and $109 \pm 48$ degrees $^{2}$, respectively. A one-way ANOVA revealed no effect of training type on area improved $\left(F_{2,14}=0.02, p=0.98\right)$. However, there was an effect of training type (figure 2) on area of worsening (one-way ANOVA: $F_{2,14}=4.5, p=$ 0.032 ), which was driven by a single, directiontrained outlier (CB6, more than 2 SD greater than the mean). Removing this outlier eliminated the effect of training type on area worsened (one-way ANOVA: $F_{2,13}=2.54, p=0.1176$ ).

Effect of patient age, lesion age, deficit size, and number of training sessions. The area of the HVF improved $\geq 6 \mathrm{~dB}$ was not correlated with patient age (figure $\left.3 \mathrm{~A}, r=0.0105, t_{20}=0.05, p=0.48\right)$, time between initial lesion and start of training (figure $3 \mathrm{~B}$, $r=-0.1272, t_{20}=-0.56, p=0.29$ ), or the original (Humphrey-defined) deficit size (figure 3C, $r=$ 
A
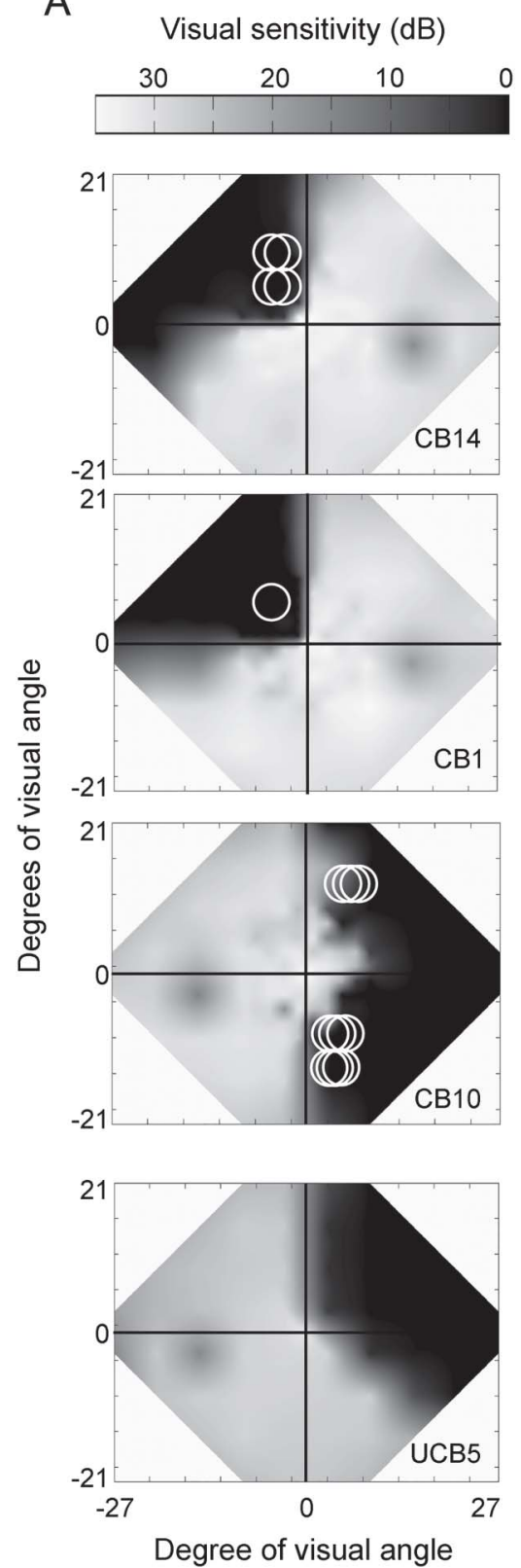

B Change in visual sensitivity $(\mathrm{dB})$
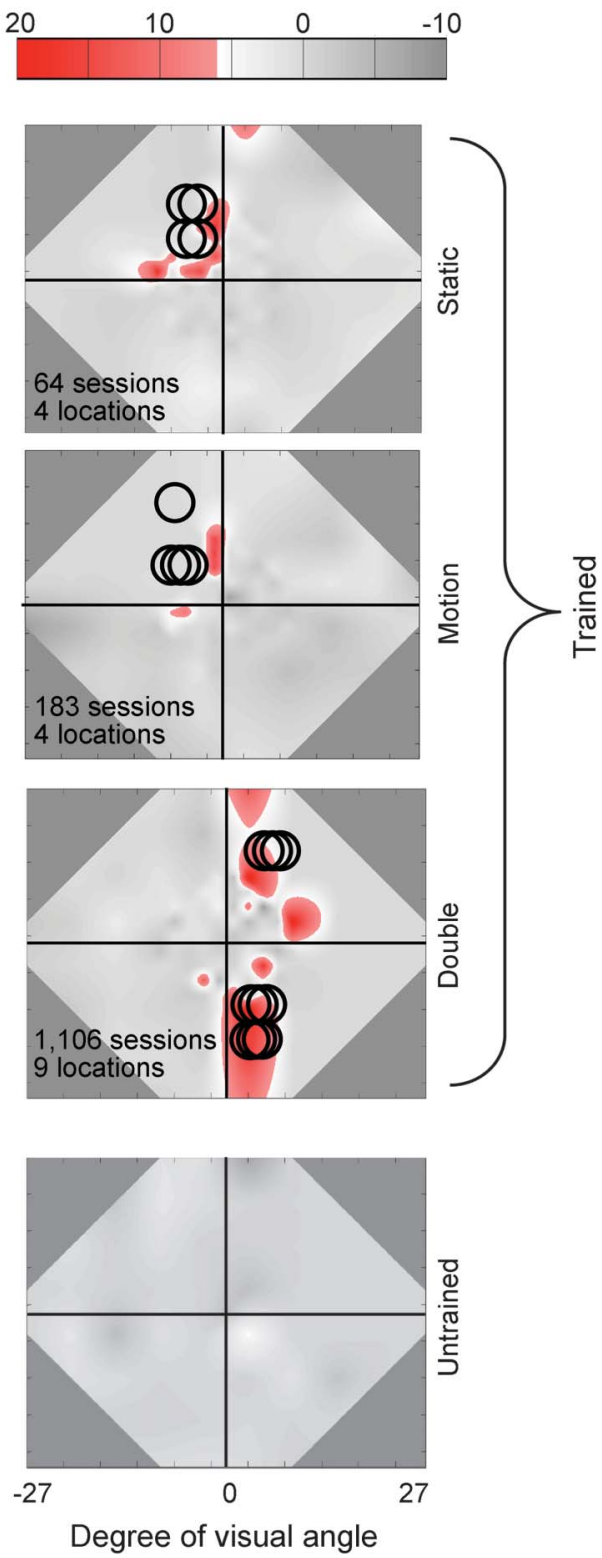

(A) Composite HVFs with circles indicating the size and location of training stimuli. (B) Difference HVF maps on the same patients as in $A$ with red hues indicating locations of significant improvement in luminance sensitivity (i.e., $\geq 6$ dB of improvement). Number of training sessions and number of locations trained are listed for each trained patient. Details of how the maps were created are provided in appendix e-1.

0.0016, $\left.t_{20}=0.01, p=0.50\right)$. However, there were near-significant correlations between the HVF area that improved and the number of training sessions performed (figure $3 \mathrm{D}, r=0.3378, t_{20}=1.6, p=$ 0.06 ), as well as between area improved and the number of locations trained (figure $3 \mathrm{E}, r=0.3408$, $t_{20}=0.162, p=0.06$ ). Removing 2 outliers (CB6 and CB13) from these datasets resulted in both correlations becoming significant (area improved/number of training sessions: $r=0.6886, t_{18}=4.03, p=0.0003$; area improved/number of training locations: $r=$ $\left.0.6448, t_{18}=3.58, p=0.001\right)$. No other correlation became significant with the removal of these 2 outliers.

Location of HVF changes. As seen in figure 2, HVF change always included, but also extended beyond, trained locations. Training locations accounted for $\sim 5 \%$ of Humphrey improvement $\geq 6 \mathrm{~dB}$ (or $4.9 \pm$ 2.3 degrees $^{2}$, figure $4 \mathrm{~A}$ ), which extended up to 29.5 degrees away (gray data points, figure 4C). Likewise, most worsening occurred outside trained locations (figure 4B). 

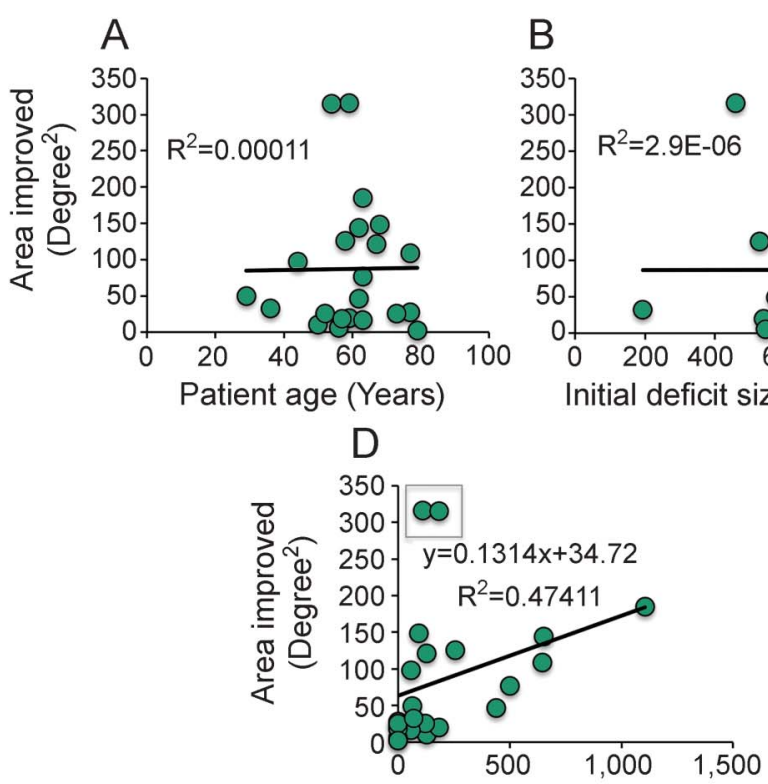

Number of training sessions
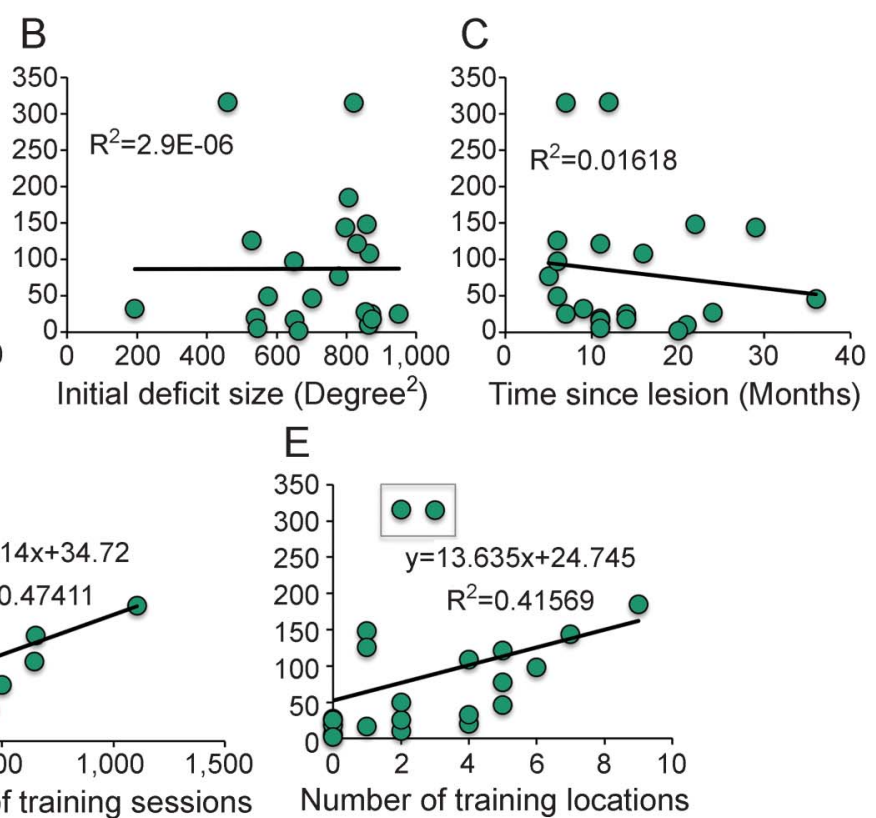

Both trained and untrained patients were included in these analyses. (A) The age of the patient at the time of recruitment did not correlate with the area of HVF improvement ( $\geq 6 \mathrm{~dB}$ ). (B) The size of the HVF-defined deficit at the time of enrollment did not correlate with the area of improvement. (C) The time between stroke and enrollment also failed to correlate with improvement. CB10 was removed as an outlier from this analysis (time since lesion was 226 months, area of improvement = 184.79 degrees $^{2}$ ). (D) The number of training sessions correlated strongly with the area of improvement measured on HVFs, as did $(E)$ the number of locations trained. $R^{2} s$ and equations are presented after removing 2 outliers. Including these outliers generates $R^{2}$ values of 0.114 for $\mathrm{D}$ and 0.116 for $\mathrm{E}$.

Most HVF improvement occurred within $5.2 \pm$ 0.7 degrees of the original blind field border $(76 \%$ occurred within 10 degrees, black data points in figure $4 \mathrm{C}$ ), and its average magnitude hovered between 9.6 and $10.4 \mathrm{~dB}$ up to $\sim 25$ degrees from this border (figure 4D).

However, $\sim 86 \%$ of HVF improvement occurred where pretraining sensitivity was between 3 and $18 \mathrm{~dB}$. Improvements dropped almost linearly above $15 \mathrm{~dB}$, with only $\sim 10 \%$ occurring where pretraining sensitivity was $>18 \mathrm{~dB}$. Similarly, only $25 \%$ of improvements occurred at locations with $0-3 \mathrm{~dB}$ of sensitivity, typically located deeper in the blind field (figure 4E). Critically, locations with $0-3 \mathrm{~dB}$ of pretraining sensitivity were where $75 \%$ of training areas were located (figure 4F), explaining the disconnect between regions of HVF improvement and training.

DISCUSSION While cortical visual impairment is thought to be irreversible, here we show that visual discrimination training reduces the size of HVF defects in chronic $\mathrm{CB}$, generating large swaths of visual improvement along the blind field border, and potentially reversing progressive vision loss. Our findings are exciting, as what little rehabilitation is currently available to patients tends to focus on eye movements (compensation therapy) ${ }^{2,19-21}$ or using prisms (substitution therapy). ${ }^{3,22}$ While these approaches improve visual functioning in daily life, ${ }^{2,19}$ neither is designed to restore vision. ${ }^{4}$ This is the purview of visual training inside CB fields (restitution therapy). ${ }^{9-13,15,16,23,24}$ However, prior to our study, there was little systematic information about how restitution training affects visual perimetry, the primary method for assessing CB fields. In addition, a significant, long-standing controversy about the efficacy of restitution therapies emerged within the field. ${ }^{7,8}$ The present work does not claim to resolve this controversy, but instead, offers new methodology to quantify changes in automated perimetry, with broad applicability to $\mathrm{CB}$, as well as other conditions affecting central vision, such as glaucoma or macular degeneration. While interpretation of our results is tempered by small sample sizes, partial blinding, and lack of randomization, bias was partially reduced because all participants were recruited with the intent to train. They were thus treated identically in terms of testing, except that some had 2 baseline HVFs, allowing us to consider native stability of HVFs. Coupled with the previously reported lack of improvement in untrained CB patients, ${ }^{1}$ our findings both motivate and inform future clinical trials designed to critically examine the effects of vision restoration on perimetry in larger cohorts of patients.

The present results expand our previous work demonstrating substantial transfer of learning across untrained visual functions. ${ }^{16-18}$ We now show that 
A

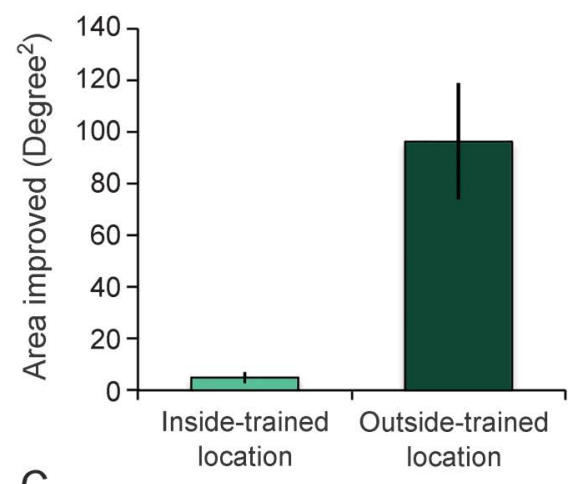

C
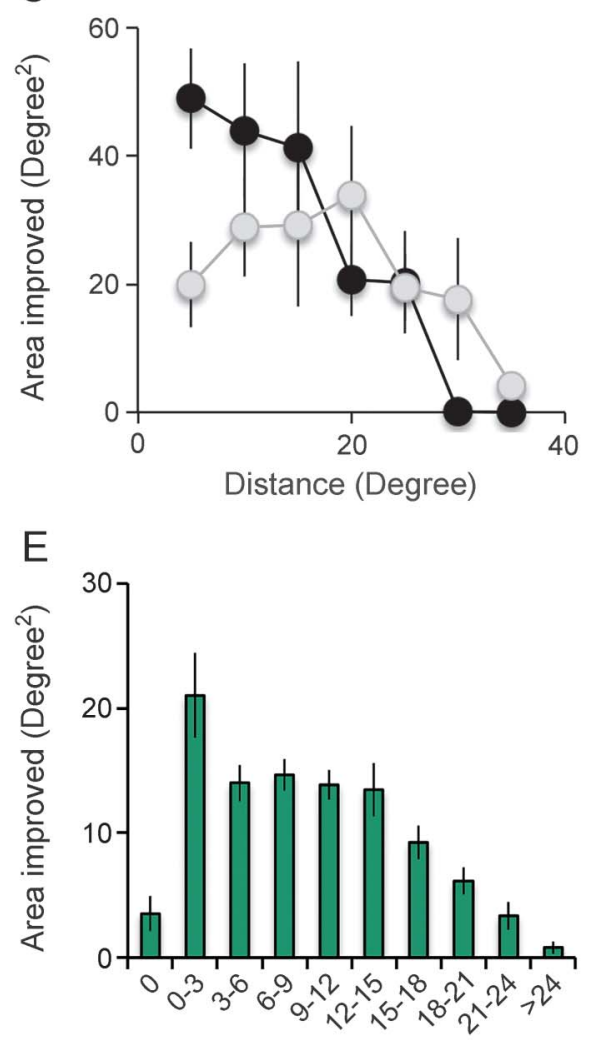

Pretraining sensitivity $(\mathrm{dB})$

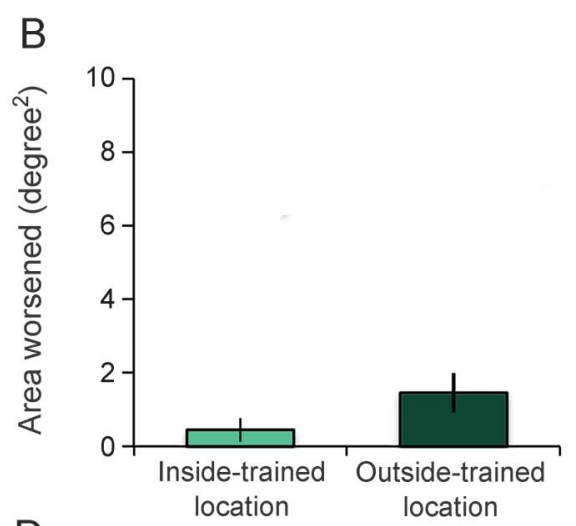

D

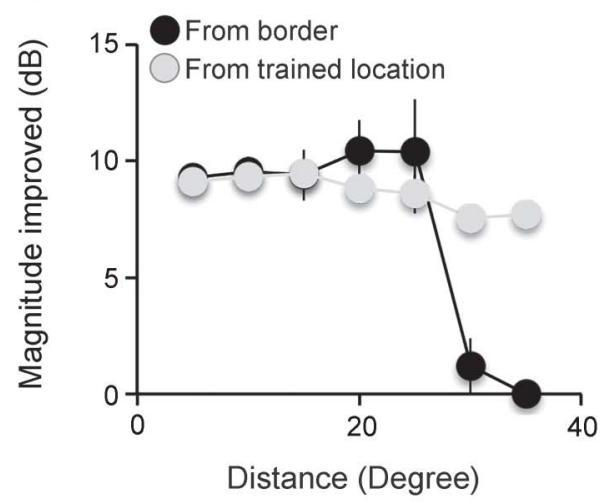

$\mathrm{F}$

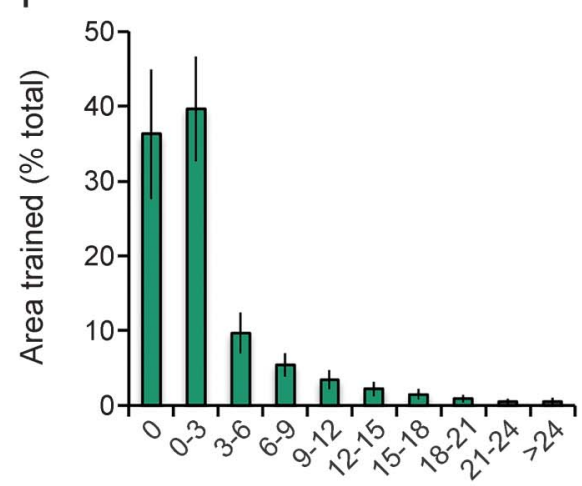

Pretraining sensitivity $(\mathrm{dB})$

(A) Area of the visual field that improved $\geq 6 \mathrm{~dB}$ inside and outside of the trained blind field locations in CB1-CB16. (B) Area of the visual field that worsened by $\geq 6 \mathrm{~dB}$ inside and outside of the trained blind field locations in CB1-CB16. (C) Area improved as a function of distance from training locations (light data points) and the pretraining blind field border (black data points). Distance was binned in 5-degree increments. (D) Plot of the average magnitude of improvement in each 5-degree distance bin. (E) Pretraining visual sensitivity in areas of the Humphrey field that improved by $\geq 6 \mathrm{~dB}$ posttraining in CB1CB16. Area improved in each bin is expressed as a percentage of the total area improved. (F) Pretraining visual sensitivities in areas of the blind field covered by training stimuli (expressed as \% of total area trained) in CB1-CB16. Bins are greater than the lower number and $\leq$ greater number. Zero bin encompasses only locations with $0 \mathrm{~dB}$ sensitivity. Values are means \pm SEM.

training chronic $\mathrm{CB}$ patients to discriminate global motion, static orientation, or both also shrinks perimetrically measured field defects. This shrinkage was associated with significant improvements in PMD $(\sim 1$ $\mathrm{dB}$ ), the small magnitude of which is likely due to the fact that PMD is computed across the entire HVF. Here, significant improvements occurred over $\sim 108$ degrees $^{2}$ or $6.6 \%$ of the total HVF. Nonetheless, prior work showed changes $\geq 0.6 \mathrm{~dB}$ to be meaningful in glaucoma patients with similarly sized visual loss as our patients. ${ }^{25}$ A PMD change of $0.7 \mathrm{~dB}$ over placebo was also considered significant in patients with idiopathic intracranial hypertension and mild visual loss (NORDIC Committee ${ }^{26}$ ). 
Critically, HVF improvements were not influenced by patient age, time since lesion, or initial deficit size (suggesting that lesion size may not affect recovery). Thus, any patient with chronic $\mathrm{CB}$ may recover some lost vision following rigorous training. However, the number of training sessions and locations correlated with the area of HVF improvement. From figure $3 \mathrm{D}$, one can estimate that substantial improvements in visual sensitivity over an area 80 degrees $^{2}$ in size can be attained with $\sim 150$ consecutive training sessions (of 300 trials each) at 2-3 blind field locations. Assuming 2 sessions/d, such training should take $\sim 3$ months to complete. However, our data also suggest that continued training may generate continued improvement. Thus, patients should train as long as improvement is observed.

HVFs repeated without intervening training revealed decreases in both local and overall (PMD) sensitivity. Whether this represents a form of visual disuse atrophy, a consequence of retrograde degeneration of neurons in the dorsal lateral geniculate nucleus (dLGN) and retina, ${ }^{27-31}$ or whether patients learned to ignore weak, unreliable vision near their blind field remains to be determined. That worsening was not systematically reported previously may be due to HVF analyses in prior studies lacking sensitivity to such changes. Nonetheless, our results suggest that visual discrimination training, even when started $>6$ months poststroke, can reverse potential declines in sensitivity.

That HVF improvements occurred within trained blind field locations is not surprising. Training to detect or discriminate stimuli in the blind field improves contrast sensitivity ${ }^{17,24}$ and HVFs are, in essence, a luminance contrast detection task with broadband stimuli. ${ }^{32,33}$ However, improvements in trained tasks are typically restricted to trained locations in CB patients, ${ }^{16,24}$ while here, $80 \%$ of HVF improvements occurred within 10 degrees of the original blind field border, suggesting enhanced plasticity in this region. In addition, close to $86 \%$ of improvements occurred where pretraining sensitivities ranged from 3 to $18 \mathrm{~dB}$, while $75 \%$ of the trained areas had baseline sensitivity $<3 \mathrm{~dB}$, a consequence of our procedure for selecting training locations. These findings highlight an interesting difference in visual functions assessed by clinical perimetry vs laboratory psychophysics: namely regions with $<3 \mathrm{~dB}$ sensitivity on Humphrey perimetry appear to possess measurable, residual visual abilities, which can be retrained back to normal.

While speculative, a possible substrate of traininginduced visual improvements in $\mathrm{CB}$ is engagement of extrageniculostriate pathways. Projections from the dLGN that bypass $\mathrm{V} 1$ provide direct input to $\mathrm{V} 2 /$ $\mathrm{V} 3,{ }^{34-36} \mathrm{~V} 4{ }^{29}$ and MT/MST. ${ }^{37}$ These pathways may mediate blindsight ${ }^{38}$ — residual visual processing present in some CB fields. ${ }^{39,40}$ After V1 damage, extrageniculostriate pathways are thought to rely primarily on koniocellular (K-cell), as opposed to parvocellular (P-cell) and magnocellular (M-cell), dLGN neurons, partly because K-cells appear to be more resistant to retrograde degeneration. ${ }^{30,41} \mathrm{~K}$-cells also possess contrast sensitivity and spatial frequency preferences that match responses seen in blindsight ${ }^{42}$ and our patients posttraining. ${ }^{17}$ Finally, K-cell pathways may switch from a modulatory to a driving role following damage to V1. ${ }^{35}$ Repeated, directed activation of these pathways through visual discrimination training could strengthen their driving role. This in turn may allow the residual visual system to better utilize information bypassing V1, measurably improving conscious vision both perimetrically and in visual discrimination tasks.

We used a fine-grained, quantitative analysis of HVFs to show that visual discrimination training at discrete blind field locations can generate large swaths of visual improvement and may prevent progressive vision loss in chronic $\mathrm{CB}$ patients. Together with the observed benefit of visual discrimination training on perimetry, the lack of effect of time since lesion on recovery suggests that a controlled, randomized, blinded, crossover clinical trial would be the optimal design to further elucidate this phenomenon in a larger patient population. Despite the limitations inherent in this pilot study, our findings remain exciting for several reasons. First, they illustrate yet another form of learning transfer in $\mathrm{CB}$ : a recovery of luminance sensitivity following visual discrimination training in which neither luminance nor contrast was varied. Second, this boost in sensitivity was reliably reported by $\mathrm{CB}$ patients during perimetry and can presumably be used in their day-to-day lives. Third, the amount of perimetry improvement attained did not depend on major demographic parameters, but was proportional to the amount of training performed. Finally, training-induced sensitivity improvements occupied previously impaired regions along the blind field border. Together, these data provide compelling evidence that contrary to established thought, cortical visual impairment is reversible in part. Specifically, visual discrimination training in chronic CB fields improves fixation-controlled visual performance on both the trained tasks and Humphrey perimetry.

\section{AUTHOR CONTRIBUTIONS}

Matthew Cavanaugh: study concept and design, data acquisition, analysis, and interpretation. Krystel Huxlin: study concept and design, data interpretation, study supervision.

\section{ACKNOWLEDGMENT}

The authors thank Terrance Schaefer for performing Humphrey visual field tests on all the patients and Drs. David Heeger, Elisha Merriam, and Duje Tadin for their constructive comments on the manuscript. 


\section{STUDY FUNDING}

This work was supported by grants from the NIH (EY021209 to K.R.H., Core Center Grant P30 EY001319 to the Center for Visual Science [CVS], training grant T32 EY007125 to CVS) and by an unrestricted grant from the Research to Prevent Blindness (RPB) Foundation to the Flaum Eye Institute.

\section{DISCLOSURE}

The authors report no disclosures relevant to the manuscript. Go to Neurology.org for full disclosures.

Received November 16, 2016. Accepted in final form February 1, 2017.

\section{REFERENCES}

1. Zhang X, Kedar S, Lynn M, Newman N, Biousse V. Natural history of homonymous hemianopia. Neurology 2006;66:901-905.

2. Spitzyna GA, Wise RJ, McDonald SA, et al. Optokinetic therapy improves test reading in patients with hemianopic alexia: a controlled trial. Neurology 2007;68:1922-1930.

3. Peli E. Field expansion for homonymous hemianopia by optically induced peripheral exotropia. Optom Vis Sci 2000;77:453-464.

4. Lane AR, Smith DT, Ellison A, Schenk T. Visual exploration training is no better than attention training for treating hemianopia. Brain 2010;133:1717-1728.

5. Pollock A, Hazelton C, Henderson CA, et al. Interventions for visual field defects in patients with stroke. Cochrane Database Syst Rev 2011;10:CD008388.

6. Melnick MD, Tadin D, Huxlin KR. Relearning to see in cortical blindness. Neuroscientist 2016;22:199-212.

7. McFadzean RM. NovaVision: vision restoration therapy. Curr Opin Ophthalmol 2006;17:498-503.

8. Horton JC. Disappointing results from Nova Vision's visual restortation therapy. Br J Ophthalmol 2005;89:1-2.

9. Chokron S, Perez C, Obadia M, Gaudry I, Laloum L, Gout O. From blindsight to sight: cognitive rehabiliation of visual field defects. Restorative Neurol Neurosci 2008;26:305-320.

10. Bergsma DP, Elshout JA, van der Wildt GJ, van den Berg AV. Transfer effects of training-induced visual field recovery in patients with chronic stroke. Top Stroke Rehabil 2012;19:212-225.

11. Bergsma DP, van der Wildt GJ. Visual training of cerebral blindness patients gradually enlarges the visual field. $\mathrm{Br} \mathrm{J}$ Ophthalmol 2009;94:88-96.

12. Raemaekers M, Bergsma D, van Wezel R, can der Wildt $\mathrm{G}$, van den Berg A. Effects of vision restoration training on early visual cortex in patients with cerebral blindness investigated with functional magnetic resonance imaging. J Neurophysiol 2011;105:872-882.

13. Raninen A, Vanni S, Hyvarinen L, Nasanen R. Temporal sensitivity in a hemianopic visual field can be improved by long-term training using flicker stimulation. J Neurol Neurosurg Psychiatry 2007;78:66-73.

14. Sahraie A, Trevethan CT, MacLeod MJ. Temporal properties of spatial channel of processing in hemianopia. Neuropsychologia 2008;46:879-885.

15. Vaina LM, Soloviev S, Calabro FJ, Buonanno F, Passingham R, Cowey A. Reorganization of retinotopic maps after occipital lobe infarction. J Cogn Neurosci 2014;26:1266-1282.

16. Huxlin K, Martin T, Kelly K, et al. Perceptual relearning of complex visual motion after V1 damage in humans. J Neurosci 2009;29:3981-3991.
17. Das A, Tadin D, Huxlin KR. Beyond blindsight: properties of visual relearning in cortucally blind fields. J Neurosci 2014;34:11652-11664.

18. Cavanaugh M, Zhang R, Melnick M, et al. Visual recovery in cortical blindness is limited by high internal noise. J Vis 2015;15:1-18.

19. Weinberg J, Diller L, Gordo WA, et al. Visual scanning training effect on reading-related tasks in acquired right brain damage. Arch Phys Med Rehabil 1977;58.

20. Kerkhoff G. Restorative and compensatory therapy approaches in cerebral blindness: a review. Restorative Neurol Neurosci 1999;15:255-271.

21. Kerkhoff G. Neurovisual rehabiliation: recent developments and future directions. J Neurol Neurosurg Psychiatry 2000;68:691-706.

22. Rossi PW, Khefyets S, Reding MJ. Fresnel prisms improve visual perception in stroke patients with homonymous hemianopia or unilateral visual neglect. Neurology 1990; 40:1597-1599.

23. Sahraie A, Trevethan CT, MacLeod MJ, Murray AD, Olson JA, Weiskrantz L. Increased sensitivity after repeated stimulation of residual spatial channels in blindsight. Proc Natl Acad Sci USA 2006;103:1497114976.

24. Sahraie A, Trevethan CT, Weiskrantz L, et al. Spatial channels of visual processing in cortical blindness. Eur J Neurosci 2003;18:1189-1196.

25. Tattersall CL, Vernon SA, Menon GJ. Mean fluctuation in eyes with stable Humphrey 24-2 visual fields. Eye 2007; 21:362-366.

26. NORDIC Idiopathic Intracranial Hypertension Study Group Writing Committee, Wall M, McDermott MP, Kieburtz KD, et al. Effect of acetazolamide on visual function in patients with idiopathic intracranial hypertension and mild visual loss: the idiopathic intracranial hypertension treatment trial. JAMA 2014;11:1641-1651.

27. Cowey A, Alexander I, Stoerig P. Transneuronal retrograde degeneration of retinal ganglion cellss and optic tract in hemianopic monkeys and humans. Brain 2011;134: 2149-2157.

28. Jindahra P, Petrie A, Plant G. Retrograde trans-synaptic retinal ganglion cell loss identified by optical coherence tomography. Brain 2009;132:628-634.

29. Cowey A, Stoerig P. Projection patterns of surviving neurons in the dorsal lateral geniculate nucleus following discrete lesions of striate cortex: implications for residual vision. Exp Brain Res 1989;75:631-638.

30. Cowey A, Stoerig P, Perry VH. Transneuronal retrograde degeneration of retinal ganglion cells after damage to striate cortex in macaque monkeys: selective loss of $\mathrm{P}$ beta cells. Neuroscience 1989;29:65-80.

31. Millington RS, Yasuda CL, Jindahra P, et al. Quantifying the pattern of optic tract degeneration in human hemianopia. J Neurol Neurosurg Psychiatry 2014;85:379386.

32. Kraft A, Roehmel J, Olma MC, Schmidt S, Irlbacher K, Brandt SA. Transcranial direct current stimulation affects visual perception measured by threshold perimetry. Exp Brain Res 2010;207:283-290.

33. Carl Zeiss Meditec Inc. Humphrey Field Analyzer User Manual. Dublin, CA: Carl Zeiss Meditec Inc.; 2010.

34. Bullier J, Kennedy H. Projection of the lateral geniculate nucleus onto cortical area V2 in the macaque monkey. Exp Brain Res 1983;53:168-172. 
35. Schmid M, Panagiotaropoulos T, Augath M, Logothetis $\mathrm{N}$, Smirnakis $S$. Visually driven activation in macaque areas V2 and V3 without input from the primary visual cortex. PLoS One 2009; 4:e5527.

36. Hendry SH, Reid RC. The koniocellular pathway in primate vision. Annu Rev Neurosci 2000;23:127-153.

37. Sincich LC, Park KF, Wohlgemuth MJ, Horton JC. Bypassing V1: a direct geniculate input to area MT. Nat Neurosci 2004;7:1123-1128.

38. Schmid MC, Mrowka SW, Turchi J, et al. Blindsight depends on the lateral geniculate nucleus. Nature 2010; 466:373-377.
39. Weiskrantz L, Warrington EK, Sanders MD, Marshall J. Visual capacity in the hemianopic field following restricted occipital ablation. Brain 1974;97:709-728.

40. Sanders MD, Warrington EK, Marshall J, Weiskrantz L. "Blindsight": vision in a field defect. Lancet 1974;1:707708.

41. Dineen J, Hendrickson A, Keating EG. Alterations of retinal inputs following striate cortex removal in adult monkey. Exp Brain Res 1982;47:446-456.

42. Ajina S, Rees G, Kennard C, Bridge H. Abnormal contrast responses in extrastriate cortex of blindsight patients. J Neurosci 2015;35:8201-8213.

\section{We're Looking for the Next Generation of Leaders- Apply for Emerging Leaders Program!}

Are you looking to take your career to the next level? We're looking for you! Applications are now open for a prestigious and interactive six-month program designed to identify, engage, and mentor AAN members who are less than 10 years out of residency or training. Learn more and apply by the July 1 deadline at $A A N$.com/view/ELP.

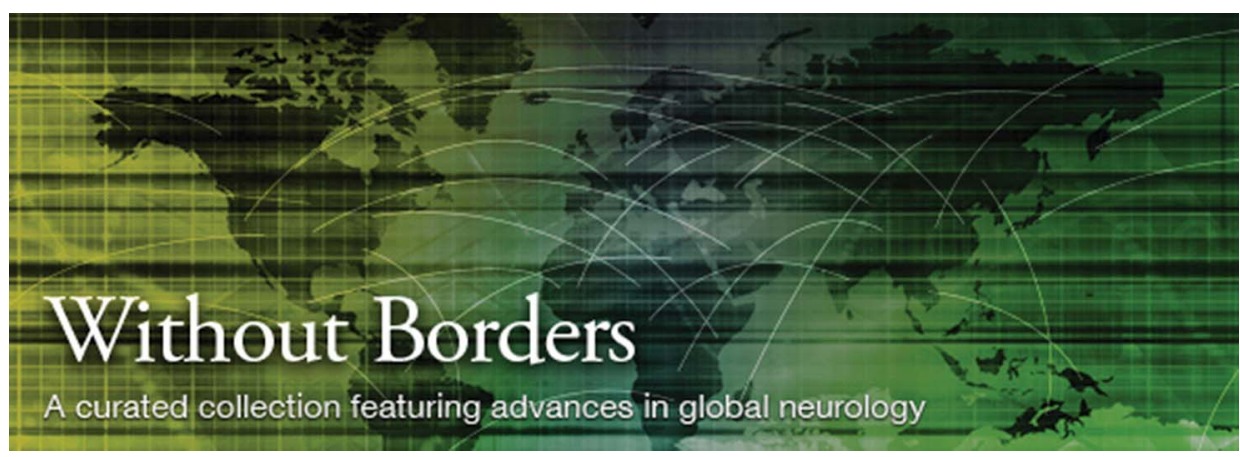

\section{NEW!}

\section{Without Borders - A curated collection featuring advances in global neurology}

This Neurology ${ }^{\circledR}$ special interest Web site is the go-to source for tracking science and politics of neurology beyond the United States, featuring up-to-the-minute blogs, scholarly perspectives, and academic review of developments and research from Neurology journals and other sources. Curated by Gretchen L. Birbeck, MD, MPH.

Expand your world view at Neurology.org/woborders. 


\section{Neurology}

\section{Visual discrimination training improves Humphrey perimetry in chronic cortically induced blindness \\ Matthew R. Cavanaugh and Krystel R. Huxlin \\ Neurology 2017;88;1856-1864 Published Online before print April 12, 2017}

DOI 10.1212/WNL.0000000000003921

This information is current as of April 12, 2017

Neurology ${ }^{\circledR}$ is the official journal of the American Academy of Neurology. Published continuously since 1951, it is now a weekly with 48 issues per year. Copyright Copyright $@ 2017$ The Author(s). Published by Wolters Kluwer Health, Inc. on behalf of the American Academy of Neurology.. All rights reserved. Print ISSN: 0028-3878. Online ISSN: 1526-632X.

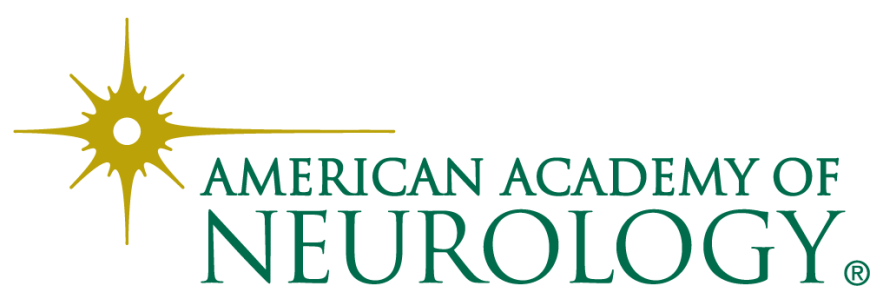




\section{Updated Information \& Services}

\section{Supplementary Material}

\section{References}

Citations

Subspecialty Collections

\section{Permissions \& Licensing}

\section{Reprints}

including high resolution figures, can be found at: http://n.neurology.org/content/88/19/1856.full

Supplementary material can be found at: http://n.neurology.org/content/suppl/2017/04/12/WNL.0000000000003 921.DC1

This article cites 40 articles, 11 of which you can access for free at: http://n.neurology.org/content/88/19/1856.full\#ref-list-1

This article has been cited by 3 HighWire-hosted articles: http://n.neurology.org/content/88/19/1856.full\#\#otherarticles

This article, along with others on similar topics, appears in the following collection(s):

\section{All Cerebrovascular disease/Stroke}

http://n.neurology.org/cgi/collection/all_cerebrovascular_disease_strok e

All Rehabilitation

http://n.neurology.org/cgi/collection/all_rehabilitation

Visual fields

http://n.neurology.org/cgi/collection/visual_fields

Visual loss

http://n.neurology.org/cgi/collection/visual_loss

Visual processing

http://n.neurology.org/cgi/collection/visual_processing

Information about reproducing this article in parts (figures,tables) or in its entirety can be found online at:

http://www.neurology.org/about/about_the_journal\#permissions

Information about ordering reprints can be found online:

http://n.neurology.org/subscribers/advertise

Neurology ${ }^{\circledR}$ is the official journal of the American Academy of Neurology. Published continuously since 1951, it is now a weekly with 48 issues per year. Copyright Copyright ( 2017 The Author(s). Published by Wolters Kluwer Health, Inc. on behalf of the American Academy of Neurology.. All rights reserved. Print ISSN: 0028-3878. Online ISSN: 1526-632X.

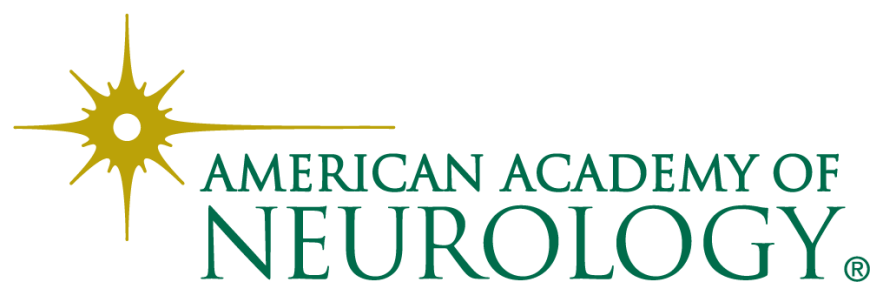

